\title{
Innovative Technologies in Production of Malt Extract
}

\author{
Elena A. Safonova \\ Department of technological design of food production \\ Kemerovo state University \\ Kemerovo, Russia \\ e-mail: safonova.kem@yandex.ru \\ Vitaly N. Ivanets \\ Department of technological design of food production \\ Kemerovo state University \\ Kemerovo, Russia
}

\author{
Dmitry M. Borodulin \\ Department of technological design of food production \\ Kemerovo state University \\ Kemerovo, Russia \\ e-mail: borodulin_dmitri@list.ru \\ Sergey S. Komarov \\ Department of technological design of food production \\ Kemerovo state University \\ Kemerovo, Russia \\ e-mail: tppp@kemsu.ru
}

\author{
Kirill M. Sidorin \\ Department of technological design of food production \\ Kemerovo state University \\ Kemerovo, Russia \\ e-mail: sidorin.1993@mail.ru
}

\begin{abstract}
This article proposes an improvement in the mashing stage in the preparation of malt extract using new modern equipment - a rotary pulsation apparatus. During the operation of such devices, pulsations, deformations, vibrations in the extractant medium, cavitation and grinding occur in them.

In the proposed new design of the rotary pulsation apparatus, the time spent on the presence of the processed product inside the apparatus is increased by organizing the recirculation of the material flow, which leads to an increase in the efficiency of the extraction process and, as a consequence, to an increase in the yield of the target components. On the basis of the studies, the optimal and rational technical and technological operating parameters of the apparatus have been determined: the inter-cylinder clearance is $0.1 \mathrm{~mm}$, the rotor speed is $1500 \mathrm{rpm}$, the duration of the process is 12 minutes, and the temperature of the medium is $70 \circ \mathrm{C}$. The time of the process of mashing by the new technology has been reduced 12 times, in comparison with the classical one. Mathematical models corresponding to the actual extraction process have been developed, since the relative error between experimental and theoretical values is no more than $8 \%$.
\end{abstract}

Keywords-rotary pulsation apparatus; mashing; malt extract; mash; extraction; malt

\section{INTRODUCTION}

Increasing the productivity of technological processes of processing plant materials, reducing their energy intensity and material consumption, improving the quality of food products are the main objectives of the agrarian and food industries. To achieve them, high-performance equipment is designed and manufactured, in which various physicochemical processes and phenomena based on impulse energy impacts using internal and external energy sources are used. These include hydromechanical cavitation $[1,2,3]$ and the generation of acoustic elastic vibrations [4, 5]. Examples of their applications for intensification of homogenization, dispersion, emulsification [6], mass transfer [7, 8, 9], disinfection [10, 11], etc. are known. The use of these phenomena is considered in the brewing industry to shorten the mashing time, activate brewer's yeast [12], produce gluten-free beer [13, 14], and in winemaking - to optimize the extraction process [15]

The purpose of the work is to improve the mashing stage in the preparation of malt extract with the use of new modern equipment that will significantly increase the yield of extractives and reduce the time of its production. Malt extract is a concentrated or dried essence, made from barley, wheat or rye malt. Characteristic properties of malt are acquired by malting. The purpose of malting is the accumulation in the grains of hydrolytic enzymes in a free state in an amount necessary to convert insoluble substances into soluble substances and to achieve the state of the grain structure, under which, under favorable conditions, the action of enzymes on the high-molecular compounds of grain would be facilitated.

Most malt varieties are used in the food industry in the preparation of various additives in dough for baking, feed for livestock, malt milk, breakfast cereals, and brewing. Various malt preparations are used as enzymatic preparations and improvers of organoleptic and nutritional properties of bakery products. Such supplements are natural, contain natural 
nutrients and guarantee good digestibility of the product by the human body.

The classical technology for obtaining malt extract includes the following production steps: obtaining malt from barley; moisturizing; extruding; cooling; crushing malt; preparation of mash; hydrolysis of the mash; subsequent separation (filtration); evaporation of wort; bottling of the finished product.

Mashing is an extraction process. The use of the extraction method, in which grinding, pulsations, deformation, vibration in the extractant environment are present, allows increasing the efficiency and speed of the process.

This can be explained by the following:

1) with intensive action on particles, strong turbulent currents and hydrodynamic microflows appear, which promote mass transfer and dissolution of substances. This is noted outside the dry particles and inside them;

2) when the material particles vibrate at the points of friction, an increase in temperature occurs, as a result of which the viscosity of the extractant decreases and the coefficient of internal diffusion increases;

3) with an increase in turbulence, the structure of the adjacent layers is disrupted, as a result of which the thickness of the boundary diffusion layer decreases;

4) under strong oscillations, the tension and compression zones alternate. Under stretching in the extractant, cavities of fluid rupture (cavitation zones) appear, which collapse with a force of several hundred atmospheres. This leads to an increase in the interfacial surface.

The above-discussed phenomena are successfully realized in rotor-pulsating apparatuses. Their distinctive characteristic is that the processed liquid is simultaneously the source and object of hydromechanical oscillations. Mechanical energy is converted into acoustic and cavitation ones without intermediate transformations. Therefore, the efficiency of these devices is quite high.

\section{METHODS AND MATERIALS OF RESEARCH}

As a result of the analysis of the extraction equipment, a new design of the rotary pulsation apparatus has been developed (Fig. 1) and its efficiency has been investigated for carrying out the mashing process.

The device consists of a casing 1 with a rotor 2 installed in it, in the hub of which there are holes 3 and a stator 4 . The rotor and stator are made in the form of coaxial cylinders with rectangular grooves in them. The conjugate surfaces of the rotor and stator are conical. The stator with the teeth is rigidly fixed to the cover 5 . In the lower part of the body there is an outlet pipe with a gripping blade 6 and a recycle channel 7 . The branch pipe 8 serves for the input of the components, and the branch pipe 9 for the withdrawal of the components. To cool or heat the product, the apparatus body is provided with a heat jacket 10 with fittings 11 and 12 . The apparatus has outer working region 13 located between the inner wall of the housing and the stator teeth and the inner working region 14 inside the rotor.

The rotary pulsation apparatus works as follows. The liquid and dry phases are fed through the inlet pipe 8 into the inner working area 14, whereby the material flow passes through the teeth of the rotor 2 and the stator 4 under the action of centrifugal forces, and enters the outer working area 13 , while the dry matter is subjected to grinding, abrasion and shock loads.

As the rotor 2 rotates, the rotor and stator slots overlap, resulting in flow pulsations and cavitation phenomena. The first part of the material flow enters through the outlet pipe with gripping blade 6 into recycle channel 7 and is directed through pipe 8 to inner working area 14 for further processing of the product in the apparatus and its mixing with the newly arrived components of the dry and liquid phases.

The second part of the product is processed in the outer working area of the apparatus 13. The finished product is discharged through the branch pipe 9 . Then the movement and recirculation of material flows are repeated.

The number of outlet nozzles with a gripping blade and their height can vary depending on the nature of the treatment of the product and the degree of its recycling.

Thus, in the developed design of the rotary pulsation apparatus, the time spent on the processed product inside the apparatus is increased, which leads to an increase in the efficiency of the extraction process and, as a consequence, to an increase in the yield of the target components.

For the study of the stage of mashing in the rotary pulsation apparatus, drinking water (GOST R 2874-82) as an extractant and malt of three sorts have been used in the preparation of the malt extract: Belgian, Finnish wheat, German "Pilsner". Each malt characteristics are presented in Table 1.

TABLE I. PHYSICAL AND CHEMICAL CHARACTERISTICS OF MALT

\begin{tabular}{|c|c|c|c|}
\hline \multirow{2}{*}{ Indicators } & \multicolumn{3}{|c|}{ Variety of malt } \\
\cline { 2 - 4 } & Belgian & $\begin{array}{c}\text { Finnish } \\
\text { wheat }\end{array}$ & $\begin{array}{c}\text { German } \\
\text { "Pilsner" }\end{array}$ \\
\hline Humidity, \% & 6.6 & 7.9 & 7.9 \\
\hline Solids content, \% & 8.4 & 8.7 & 8.8 \\
\hline Density, g/ cm ${ }^{2}$ & 1.0335 & 1.035 & 1.0355 \\
\hline Extractivity, \% & 77.668 & 82.862 & 83.815 \\
\hline
\end{tabular}

The apparatus operating in a stationary mode has been loaded with malt and water in a ratio of 1:4 and mashing has been carried out with a gap between the rotor and the stator of $0.1 \mathrm{~mm}$. Variable factors of the experiment are:

- $\quad$ processing time in the device $\tau-6,12,18 \mathrm{~min}$;

- $\quad$ processed medium temperature $\mathrm{t}-65,70,75^{\circ} \mathrm{C}$;

- $\quad$ rotor speed n - 1200; 1500; 1800 rpm. 


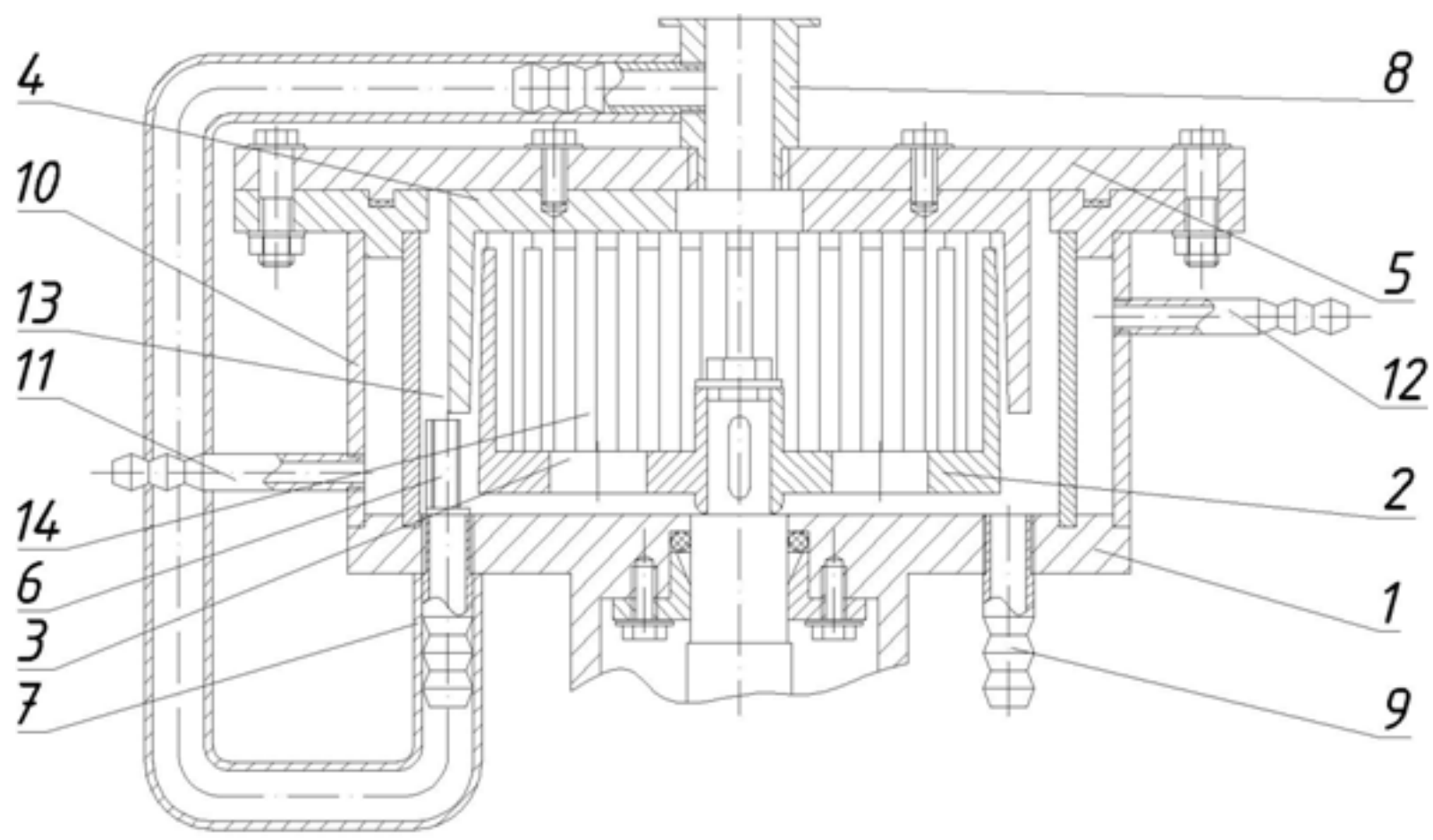

Fig. 1. Rotary pulsation apparatus: 1 - body, 2 - rotor, 3 - holes in the hub, 4 - stator, 5 - cover, 6 - outlet with a gripping blade, 7 - recycle channel, 8 - branch pipe for the input of components, 9 - 10 - heat jacket, 11, 12 - nozzles, 13 - external working area, 14 - inner working area

Every two minutes, sampling was carried out with the apparatus in operation. The main extract of malt was the concentration of the target component in the final mash C, which was determined by drying each sample in a drying cabinet. The malt extract, obtained by classical technology served as a control sample.

In the course of the research, the power consumed by the engine, depending on the rotor speed, has been determined. For this purpose, an ammeter and a voltmeter were installed on a laboratory bench. With the sampling of each sample, the current and voltage were measured, after which the power consumption of the apparatus has been calculated.

\section{RESULTS AND DISCUSSION}

Based on the obtained experimental data, the surfaces of the dependence of the concentration of dry matter in the malt extract on the duration of the mashing process in the rotary pulsation apparatus and the temperature of the treated medium at the rotor rotation frequency of 1200, 1500 and $1800 \mathrm{rpm}$ have been constructed. Fig. 2, 3 and 4 show surface data at a rotor speed of $1500 \mathrm{rpm}$ for the Belgian, Finnish wheat and German "Pilsner" malt varieties, respectively.

To evaluate the functional relationship between the independent variables $\tau, \mathrm{t}, \mathrm{n}$ and the $\mathrm{C}$ response, the results of the experiments have been processed by the multiple regression analysis in the program STATISTICA 8.0.

For Belgian malt, the following equation is obtained:
$\mathrm{C}=-241.18+6.73 \cdot \mathrm{t}+2.73 \cdot \tau-0.03 \cdot \mathrm{t} \cdot \tau-0.05 \cdot \mathrm{t}^{2}-$ $0.03 \cdot \tau^{2}$

As can be seen, in the equation 1 there is no variable $n$. This is due to its insignificant influence within the limits of $1200 \ldots 1800 \mathrm{rpm}$ on the obtained concentration of the target component in the final mash (dry matter content).

The resulting regression model (1) has the following indicators. The coefficient of multiple correlation $\mathrm{R}=$ 0.81063723 is close to 1 , which indicates a large dependence of the output variable on these parameters. The coefficient of determination is $\mathrm{R}^{2}=0.75921013$.

This means that the constructed regression explains more than $76 \%$ of the variance of the values of the variable with respect to the average value. The Fisher Criterion $\mathrm{F}=$ 78.97 - is of sufficient importance to state that the model is adequate and can be used to predict the solids content in the extract.

The model described is statistically significant, since the significance level is $p=0.000404$. This means that a model with zero probability will only be a random coincidence for a given sample.

The experimental values of the dry matter concentration were compared with those predicted by the regression mathematical model (1). The average relative error between the data was about $6 \%$, which is allowed for engineering calculations. The regression equation for the Belgian malt has been obtained in a similar way:

$\mathrm{C}=-366.1+10.06 \cdot \mathrm{t}+3.95 \cdot \tau-0.04 \cdot \mathrm{t} \cdot \tau-0.07 \cdot \mathrm{t}^{2}-$ $0.04 \cdot \tau^{2}$. 


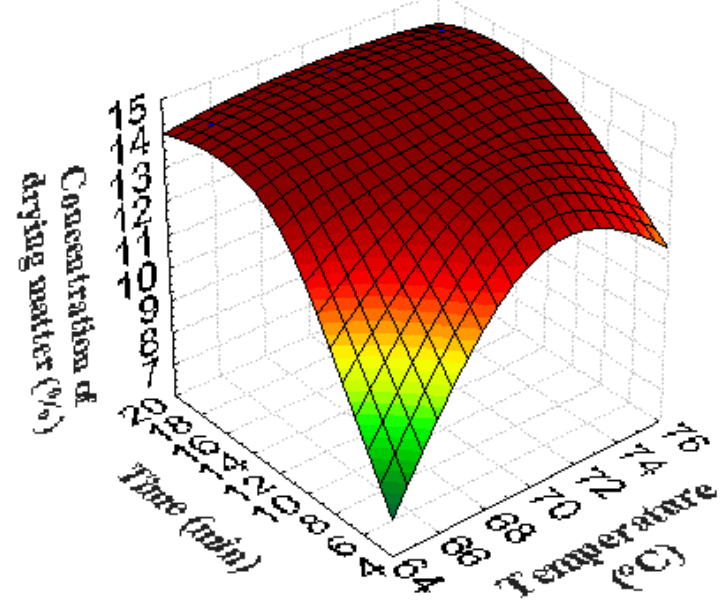

Fig. 2. Dependence of the concentration of dry matter in the malt extract on the duration of the mashing process and the medium temperature of the Belgian malt

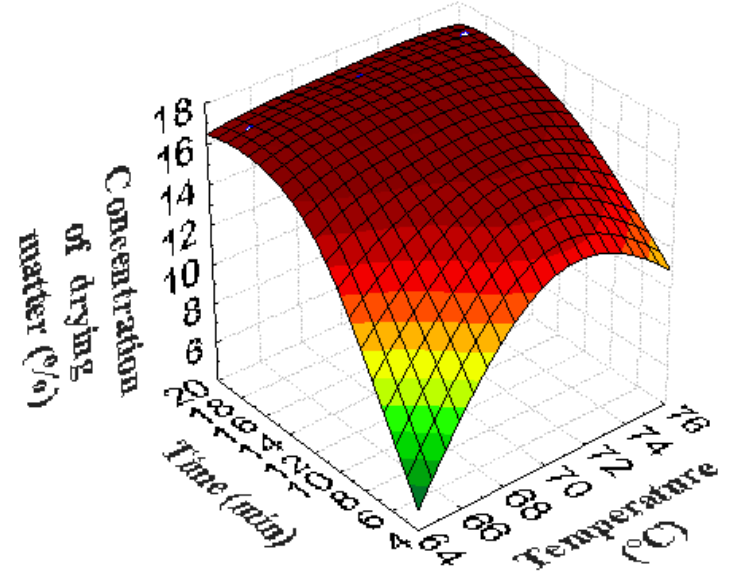

Fig. 3. Dependence of the concentration of dry matter in the malt extract on the duration of the mashing process and the medium temperature of the Finnish wheat malt

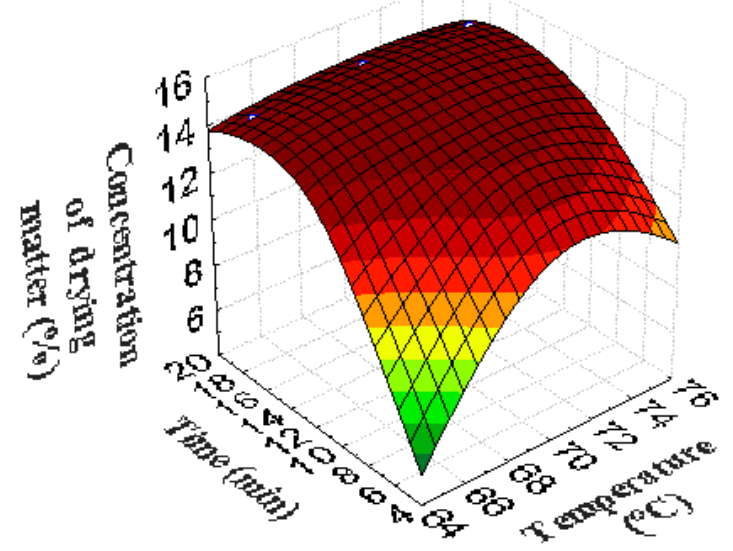

Fig. 4. Dependence of the concentration of dry matter in the malt extract on the duration of the mashing process and the medium temperature of the German "Pilsner" malt
The estimation data of the obtained model (2) showed that the model is adequate and can be used to predict the content of dry matter $\mathrm{C}$ in the malt extract. The average relative error between the experimental and theoretical data has been $8 \%$.

For the German malt "Pilsner", the regression equation that adequately describes the dependence has the form:

$\mathrm{C}=-245.41+6.99 \cdot \mathrm{t}+2.6 \cdot \tau-0.021 \cdot \mathrm{t} \cdot \tau-0.05 \cdot \mathrm{t}^{2}-$ $0.037 \cdot \tau^{2}$

The average relative error in the experimental and theoretical data has been $6.5 \%$.

The analysis of mathematical models allowed the optimum operating modes of the rotary pulsation apparatus for preparing the malt extract to be determined: the duration of the process is $\tau=12 \mathrm{~min}$; the temperature of the medium being treated is $\mathrm{t}-70^{\circ} \mathrm{C}$. With these parameters, a high yield of dry matter is ensured.

During the experiments, the dependence of the power consumed by the electric motor on the time of mashing in the rotary-pulsating apparatus has been determined. The obtained results of the investigations are shown in Fig. 5, 6 and 7 for the Belgian, Finnish, and German "Pilsner" malt varieties, respectively.

The graphs show that the power costs of the mashing process for different rotor speeds for each malt variety are characterized by the same regularities. At the beginning of the extraction process, a sudden increase in the power consumption occurs. This is due to the fact that the grains of malt are in the general state at the beginning of the process, and their grinding requires much more energy. Then gradually, with a decrease in the size of the grains, the power consumption is reduced.

At $\mathrm{n}=1800 \mathrm{rpm}$, the power increases significantly due to high energy costs, compared to $n=1200$ and $1500 \mathrm{rpm}$. This causes unnecessarily high energy costs. And at $\mathrm{n}=$ $1500 \mathrm{rpm}$ there is a slight increase in energy, in comparison with $\mathrm{n}=1200 \mathrm{rpm}$.

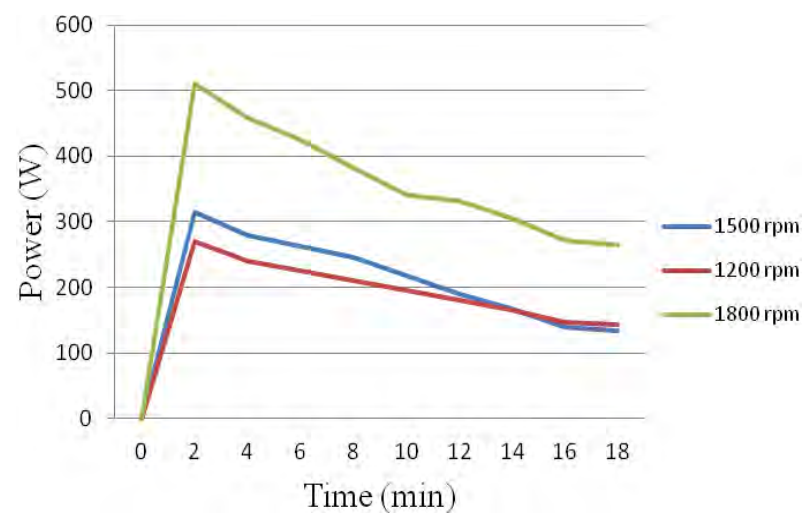

Fig. 5. Dependence of the power consumed by the electric motor on the mashing time for the Belgian malt 


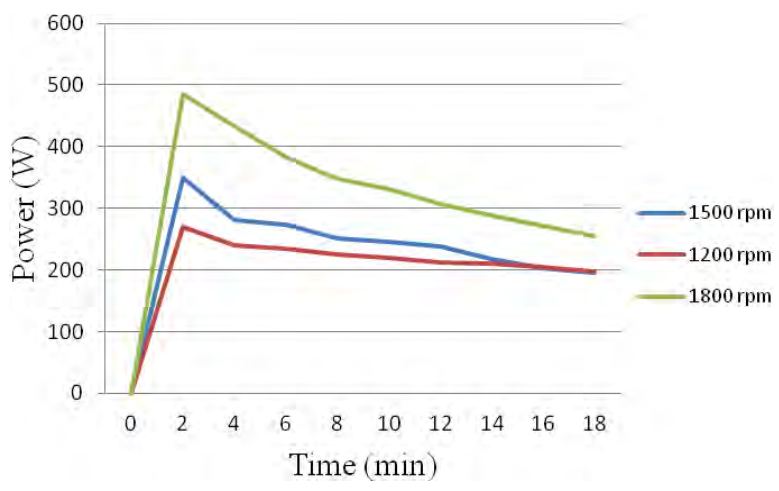

Fig. 6. Dependence of the power consumed by the electric motor on the mashing time for Finnish malt

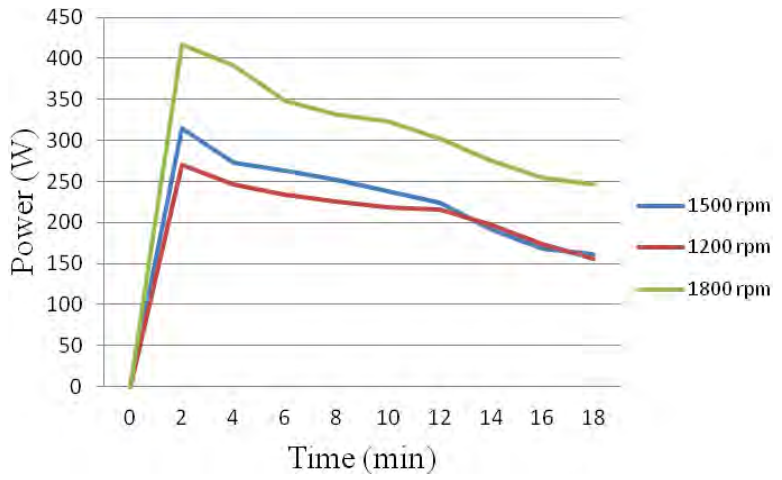

Fig. 7. Dependence of the power consumed by the electric motor on the mashing time for the German "Pilsner" malt variety

After 12 minutes of operation, the curves are aligned, indicating that the state of the stationary operation of the device has been reached. The obtained experimental data have shown that at $\mathrm{n}=1500 \mathrm{rpm}$ a somewhat better extraction occurs than at $\mathrm{n}=1200 \mathrm{rpm}$, and the power consumption increases slightly.

\section{CONCLUSION}

As a result of the research, a new design of a rotary pulsation apparatus has been developed that meets modern requirements for an effective mashing process in the preparation of a malt extract.

On the basis of theoretical and experimental data, the optimal and rational technical and technological operating parameters of the apparatus are determined: the intercylinder gap is $0.1 \mathrm{~mm}$, the rotor speed is $1500 \mathrm{rpm}$, the duration of the process is $12 \mathrm{~min}$, the medium temperature is $70^{\circ} \mathrm{C}$.

The time of the process of mashing by the new technology has been reduced 12 times, in comparison with the classical one. Mathematical models corresponding to the actual extraction process have been developed, since the relative error between experimental and theoretical values is no more than $8 \%$.

\section{References}

[1] P. Senthil Kumar, M. Siva Kumar, A.B. Pandit, "Experimental quantification of chemical effects of hydrodynamic cavitation - effect of cavitation," Chemical engineering science, 2000, vol. 55, no. 9, pp. 1633-1639.

[2] Z.A. Zhou, Z. Xu, J.A. Finch, H. Hu, S.R. Rao, "Role of hydrodynamic cavitation in fine particle flotation," International journal of mineral processing, 1997, vol. 51, no. 1-4, pp. 139-149.

[3] P.R. Gogate, A.B. Pandit, "A review and assessment of hydrodynamic cavitation as a technology for the future," Ultrasonics sonochemistry, 2005, vol. 12, no. 1 - 2, pp. $21-27$.

[4] T.J. Mason, F. Chemat, M. Ashokkumar, Power ultrasonics Applications of high-intensity ultrasound. Elsevier Inc, 2014.

[5] F. Chemat, M.K. Khan, "Applications of ultrasound in food technology: Processing, preservation and extraction," Ultrasonics sonochemistry, 2011, vol. 18, Issue 4, pp. 813 - 835

[6] H. Delmas, L. Barthe, Power ultrasonics: applications of highintensity ultrasound. Elsevier Inc, 2015.

[7] K.M. Rajkovic, M. Gavrilovic, S. Jeremic, P.S. Milic, M. Kostic, V. Arsic-Arsenijevic,B. Krstic, "Optimization of ultrasound-assisted extraction of total extractive substances from galium Verum L," Periodica polytechnica: chemical engineering, 2017, vol. 61, no. 3 , pp. 200-205.

[8] T.N. Viten'ko, YA.M. Gumnickij, "Massoobmen pri rastvorenii tverdyh tel $\mathrm{s}$ ispol'zovaniem gidrodinamicheskih kavitacionnyh ustrojstv (Use of hydrodynamic cavitational devices in extraction at dissolution of solid substances)," Theoretical bases of chemical technology, 2006, vol. 40, no. 6, pp. 639-644.

[9] K. Vilkhu, R. Mawson, L. Simons, D. Bates, "Applications and opportunities for ultrasound assisted extraction in the food industry A review," Innovative Food Science \& Emerging Technologies, 2008, vol. 9, Issue 2, pp. $161-169$.

[10] C. Jimenez-Sánchez, J. Lozano-Sanchez, A. Segura-Carretero, A Fernandez-Gutierrez, "Alternatives to conventional thermal treatments in fruit-juice processing. Part 1: techniques and applications," Critical reviews in food science and nutrition, 2017, vol. 57, no. 3, pp. 501-523.

[11] C. Jimenez-Sánchez, J. Lozano-Sanchez, A. SeguraCarretero, A. Fernandez-Gutierrez, "Alternatives to conventional thermal treatments in fruit-juice processing. Part 2: effect on composition, phytochemical content, and physicochemical, rheological, and organoleptic properties of fruit juices," Critical reviews in food science and nutrition, 2017 , vol. 57 , no. 3, pp. 637 652 .

[12] E.A. Safonova, A.N. Potapov, E.A. Vagajceva, "Intensifikaciya tekhnologicheskih processov proizvodstva piva pri ispol'zovanii rotorno-pul'sacionnogo apparata (Applications of rotary pulsation apparatus for intensification of technological processes in production of beer,") Equipment and technology of food productions, 2015, no. 1, pp. $74-81$.

[13] L. Albanese, F. Meneguzzo, R. Ciriminna, _M. Pagliaro, "Gluten reduction in beer by hydrodynamic cavitation assisted brewing of barley malts," LWT - Food Science and Technology, 2017, vol. 82, no. 1 , pp. 342-353.

[14] L. Albanese, F. Meneguzzo, R. Ciriminna, _M. Pagliaro, "Beerbrewing powered by controlled hydrodynamic cavitation: Theory and real-scale experiments," Journal of Cleaner Production, 2017, vol. 142, no. 4, pp. 1457-1470.

[15] M. Palma, C.G. Barroso, "Ultrasound-assisted extraction and determination of tartaric and malic acids from grapes and winemaking by-products," Analytica chimica acta, 2002, vol. 458, no. 1, pp. 119 130. 